\title{
A Importância dos Clássicos na Formação do PeSQUisador: O QUe nOS DIZ OS CONCEITOS DE SOCIALIZAÇÃO, IDENTIFICAÇÃO E CAMPO INTELECTUAL COMO CAMPO DE PODER
}

\author{
The Importance of Classics in the Formation of the Researcher: \\ what says to us the concept of socialization, identification and \\ intellectual field as field of power
}

\author{
Juliana Cristina Teixeira \\ Doutoranda em Administração pelo CEPEAD/UFMG. Professora Assistente. Universidade Federal de São João Del-Rei. Belo \\ Horizonte, MG. Brasil.E-mail: julianacteixeira@yahoo.com.br
}

\section{Eduardo José Zanoteli}

Doutorando em Administração pelo CEPEAD/UFMG. Professor do Departamento de Ciências Contábeis da UFES. Universidade Federal do Espírito Santo. Vitória, ES. Brasil.E-mail: eduardo.zanoteli@ufes.br

\section{Alexandre de Pádua Carrieri}

Professor Titular da Pós-Graduação e da Graduação em Administração do CEPEAD/UFMG. Universidade Federal de Minas Gerais. Belo Horizonte, MG. Brasil. E-mail: alexandre@face.ufmg.br

\section{Resumo}

O objetivo deste ensaio teórico é defender a importância da leitura dos clássicos no processo de formação e de constituição do sujeito como pesquisador. Constrói-se essa defesa por meio de abordagens teóricas relacionadas aos conceitos de socialização; de identificação (que se relaciona ao conceito de identidade); e por meio da noção bourdiesiana de que o campo intelectual é um campo de poder. Ao longo da discussão, analisa-se como, por intermédio da socialização, há uma influência tanto da estrutura quanto do próprio sujeito em sua constituição como pesquisador. Por meio do conceito de identificação, percebe-se a influência da subjetividade do sujeito pesquisador ao se identificar ou não com os clássicos que lê, escolhendo aqueles que serão os "seus" clássicos. E, por meio da noção de campo intelectual como campo de poder, considera-se a existência de uma ciência que não é desinteressada e defende-se o perigo dos apuds e da leitura de traduções dos clássicos.

Palavras-chave: Clássicos. Pesquisador. Socialização. Identificação. Campo de Poder.

\section{Abstract}

The objective of this theoretical article is defend the importance of reading of the classics in the process of formation and constitution of the subject as a researcher. We construct this defense by means of theoretical approaches related to the concepts of socialization, identification (which relates to the concept of identity); and by means of Bourdieusian notion of that intellectual field is a field of power. Throughout the discussion, we analyzed how, by means of socialization, there is an influence of the structure how of the subject itself in their constitution as researcher. By means of the concept of identification, we perceive the influence of the subjectivity of the researcher subject to the identify yourself or not with the classics that reads, choosing those who will be "their" classics. And, by means of the notion of the intellectual field as a field of power, we consider the existence of a science that is not disinterested and we defend the danger of "apuds" and reading of translations of the classics.

Keywords: Classics. Researche. Socialization. Identification. Fiel of Power. 


\section{INTRODUÇÃo}

O objetivo deste ensaio teórico é, por meio de uma releitura da obra de Ítalo Calvino ${ }^{1}$, Por que ler os clássicos, defender a importância da leitura dos clássicos no processo de formação e de constituição do sujeito como pesquisador. Para tal, foram utilizadas abordagens teóricas relacionadas aos conceitos de socialização, identificação (e identidade) e a noção do campo intelectual como um campo de poder. Sendo assim, foram acionados diferentes constructos teóricos que auxiliam na discussão da importância de se ler os clássicos, principalmente em contraposição a leituras orientadas apenas para autores contemporâneos ou "leitores" dos clássicos (tais como os famosos apuds).

Importante ressaltar também a pertinência de se fazer tal discussão aliada à relação que existe entre estrutura e sujeito nas ciências sociais. Cada um dos conceitos aqui trabalhados auxilia a pensar a influência de ambos na formação do pesquisador, bem como a influência de jogos de poder existentes no campo intelectual.

A formação do pesquisador e seu estabelecimento no campo estão significativamente relacionados à trajetória que acompanha esse pesquisador desde sua inserção no campo acadêmico (até mesmo anteriormente), trajetória essa influenciada por processos de socialização e de identificação, em que o sujeito continuamente se constrói como pesquisador, modificando-se ao longo do tempo. Em sua interação com os outros (o próprio clássico é um desses outros), em seu processo de identificação ou não com esses outros, o pesquisador vai se constituindo. Nesse processo, os clássicos adquirem um papel importante, e por maiores que sejam "[...] as leituras de formação de um indivíduo, resta sempre um número enorme de obras que ele não leu". (CALVINO, 1999, p. 9)

Essa formação é também influenciada pelos interesses e pelas tomadas de posições políticas por parte dos escritores, estudiosos ou pesquisadores no campo intelectual, o que se reverte em um alerta para que não se leia de forma ingênua os clássicos e, principalmente, os leitores desses clássicos. Pois ser pesquisador é ser político, já que assumir uma posição estética dentro do campo intelectual implica também em assumir uma tomada de posição política. (BOURDIEU, 2006)
Como forma de estruturar as discussões, o ensaio foi organizado em seis seções. Esta que ora se encerra (Seção 1) apresentou o tema proposto e o contextualizou aos conceitos que serão discutidos. $\mathrm{Na}$ Seção 2 , é feito um convite à leitura dos clássicos a partir da obra de Ítalo Calvino. Nas seções seguintes, discutem-se os conceitos de socialização (Seção 3), identificação e identidade (Seção 4) e campo intelectual como campo de poder (Seção 5), os quais são associados à leitura dos clássicos e à formação do pesquisador. Por fim, na Seção 6, são apresentadas as considerações finais, nas quais reafirma-se a defesa pela importância dos clássicos na constituição do ser-pesquisador.

\section{Por que Ler os Clássicos, por Ítalo Calvino}

Os pesquisadores poderiam se questionar: por que ler os clássicos se é possível consultar uma literatura intermediária e otimizar o tempo, concentrando a leitura em temas atuais e contemporâneos? Ou, ainda, por que envidar esforços em desbravar os clássicos se outros já o fizeram? Algumas das possíveis respostas se iniciam com outros questionamentos, como por exemplo: será que Marx foi adequadamente compreendido e estudado pelos que se dizem marxistas? Será que não tem mais nada a dizer? Será que seus seguidores, simpatizantes e críticos conseguiram captar em essência as suas ideias e pensamentos e exploraram todas as perspectivas possíveis? O mesmo se poderia questionar sobre Durkheim, Weber, Kant, Hegel, Freud, Bourdieu, Berger e Luckmann, Foucault, Popper, Markowitz, Modigliane e Miller e tantos outros clássicos. A simples dúvida quanto às respostas para essas questões, por si só, já seria um convite à leitura dos clássicos, mas muitos outros motivos se somam a estes, os quais serão discutidos neste ensaio.

Um aspecto para o qual se quer chamar atenção na defesa que se faz em relação à leitura dos clássicos é que, por haver uma tendência de que eles sejam considerados atemporais, corre-se um risco muito grande de se cair no anacronismo conceitual. Ler os clássicos não deveria ser um simples exercício de captura de conceitos, de cópia de trechos que possam explicar temas e discussões que se queira hoje realizar, como se fosse possível acionar atemporalmente. Os clássicos 
e o que eles escrevem podem ser considerados atemporais no sentido em que suas obras continuam sendo importantes para entender os contextos sobre os quais se debruçam teoricamente.

No entanto, o clássico e sua obra trazem consigo um contexto histórico e social que não pode estar deles desvinculados. Quando isso ocorre e quando, como bem chamam a atenção Matitz e Vizeu (2012), percebe-se a reunião de definições conceituais e de teorias em um único quadro teórico sem que os autores sejam historicamente situados, e sem que o "[...] sentido dado por autores de diferentes épocas ou mesmo de variados contextos nacionais [...]" (MATITZ; VIZEU, 2012, p. 589) seja considerado, o tratamento do clássico como sendo atemporal traz um efeito que é negativo para as próprias reflexões acadêmicas que, assim, acabam sendo contaminadas por um excesso de anacronismo que as descaracterizam historicamente.

Nesse sentido, argumenta-se que muitas vezes os clássicos são considerados atemporais por trazem leituras da sociedade que ainda explicam diversas facetas dos cenários sociais contemporâneos. No entanto, não podem ser desvinculados de suas perspectivas sócio-históricas. A defesa para que essas perspectivas sejam consideradas no contexto dos estudos organizacionais é realizada por Matitz e Vizeu (2012) quando os autores discutem o problema da definição conceitual nesse campo. Para os autores, o conceito, nesse campo de pesquisas, é "[...] um fenômeno socialmente referente e historicamente (re)construído, capaz de revelar diferentes estruturas sociais e sua relação com o léxico de significações que se constitui ao longo do tempo" (MATITZ; VIZEU, 2012, p. 577). Sobre esse ponto de vista, considera-se que os clássicos podem ser auxílios importantes para a compreensão dessas reconstruções temporais dos conceitos e teorias.

Calvino (1999) captura bem a importância dos clássicos e chama a atenção para o perigo da bibliografia subjacente, intermediária, que muitas vezes, com o tempo, se distancia da obra e do pensamento original dos autores, à medida que uns vão lendo pelos outros, acrescentando, suprimindo, incorporando, ignorando, confundindo, camuflando. Ele assim alerta:

Existe uma inversão de valores muito difundida segundo a qual a introdução, o instrumento crítico, a bibliografia são usados como cortina de fumaça para esconder aquilo que o texto tem a dizer e que só pode dizer se o deixarmos falar sem intermediários que pretendam saber mais do que ele. (CALVINO, 1999, p. 12)

Nesse sentido, afirma que "[...] um clássico é uma obra que provoca incessantemente uma nuvem de discursos críticos sobre si, mas continuamente a repele para longe" (CALVINO, 1999, p. 12). Repele para longe aquilo e aqueles que se afastam das ideias originais e corrompem a essência de seus conteúdos, ou seja, a nuvem que encoberta, que esconde, que obscurece e que, por fim, afasta. Provoca questionamentos tão profundos e pertinentes que as críticas se tornam desejavelmente inevitáveis e deliciosamente transformadoras. Aqui cabe um alerta aos "replicantes", são àqueles que sem um olhar crítico tanto em relação aos textos originais quanto em relação à bibliografia posterior, passivamente "levam adiante" conteúdos vazios, movidos quase sempre por modismos. O que se acredita ser indesejável para um pesquisador, para o qual o senso crítico e a reflexão são importantes. Chama-se aqui de replicantes pesquisadores que simplesmente reproduzem teorias advindas de outros autores sem necessariamente considerar sua pertinência ou adequação ao contexto de análise, ao momento histórico que essa teoria foi construída e está sendo então aplicada e também à postura ontológica e epistemológica em que foram baseadas.

Não se tratam apenas de estilo literário as referências que aqui são feitas à Calvino usando os verbos no presente (captura, chama, alerta, afirma, repele, provoca). Trata-se, antes, de uma alusão à atualidade que aparece imbricada em seus escritos. Calvino (1999, p. 11) ressalta que "[...] um clássico é um livro que nunca terminou de dizer aquilo que tinha para dizer [...]", assim, "[...] toda releitura de um clássico é uma leitura de descoberta como a primeira". Nesse sentido, afirmar que se termina de ler um clássico nem sempre é algo possível, pois sua releitura permite que se aprenda de novo, que se façam novas descobertas, mesmo que para tal seja necessário desconstruir algumas verdades para em seguida reconstruí-las e estabelecer novas (ou as mesmas) visões. Dessa forma, a atualidade do clássico pode permanecer ainda que esse seja, de fato, "velho".

O próprio sujeito que se constrói como pesquisador passa por modificações ao longo de sua trajetória. As modificações aqui enfatizadas são aquelas oriundas 
dos contatos que o sujeito tem com os clássicos. Por exemplo, depois de ler Berger e Luckmann (1985), é possível vir a admitir, ainda que antes não se tivesse tal visão, que a realidade é socialmente construída. Ainda, ao ler Foucault (2006), que o poder é relacional, e não algo possuído/detido por um indivíduo, e que a sociedade é imersa por constantes relações de vigiar e punir (FOUCAULT, 2005). Ao ler Bourdieu (1998), que todos os campos sociais estão imersos em campos de poder, ou percebe-se as relações sociais entre os sexos $e$ a dominação masculina como uma construção social. (BOURDIEU, 2007)

Nesse sentido, os clássicos têm essa capacidade de acrescentarem algo novo, não só porque nós mudamos, mas porque eles também mudam à luz de perspectivas históricas diferentes (CALVINO, 1999). Entretanto, não se pode entender que os textos contemporâneos devam ser deixados de lado, ou que os não clássicos não devam ser lidos. Refere-se e ao mesmo tempo questiona-se é que os clássicos não podem ser esquecidos ou relegados a leituras superficiais, sendo substituídos por aquilo que se taxa de "novo", "moderno" ou "pós-moderno", por exemplo.

Assim, não se pretende defender aqui que não se leia também aquilo que não é considerado clássico. Calvino (1999, p. 14-15) corrobora dizendo que

[...] o dia de hoje pode ser banal e mortificante, mas é sempre um ponto em que nos situamos para olhar para frente ou para trás. Para poder ler os clássicos, temos de definir "de onde" eles estão sendo lidos, caso contrário tanto o livro quanto o leitor se perdem numa nuvem atemporal. Assim, o rendimento máximo da leitura dos clássicos advém para aquele que sabe alterná-la com a leitura de atualidades numa sábia dosagem. E isso não presume necessariamente uma equilibrada calma interior: pode ser também o fruto de um nervosismo impaciente, de uma insatisfação trepidante. Talvez o ideal fosse captar a atualidade como o rumor do lado de fora da janela, que nos adverte dos engarrafamentos do trânsito e das mudanças do tempo, enquanto acompanhamos o discurso dos clássicos, que soa claro e articulado no interior da casa. Mas já é suficiente que a maioria perceba a presença dos clássicos como um reboar distante, fora do espaço invadido pelas atualidades como pela televisão a todo volume. Acrescentemos então: É clássico aquilo que tende a relegar as atualidades à posição de barulho de fundo, mas ao mesmo tempo não pode prescindir desse barulho de fundo. É clássico aquilo que persiste como rumor mesmo onde predomina a atualidade mais incompatível. (CALVINO, 1999, p. 14-15, grifo do autor)

Sendo assim, segundo Calvino (1999), um clássico é aquele que possui um efeito de ressonância, não somente uma obra antiga, como se pode pensar. $\mathrm{O}$ adjetivo, segundo o autor, vale também para uma obra moderna, desde que ela já tenha um lugar próprio em uma continuidade cultural. "Um clássico é um livro que vem antes de outros clássicos; mas quem leu antes os outros e depois lê aquele, reconhece logo o seu lugar na genealogia”. (CALVINO, 1999, p. 14)

Lendo ou relendo Calvino (1999) (já que este ensaio é escrito por mais de um autor), atenta-se não apenas para a importância dos clássicos em si, mas como essa discussão se relaciona a algumas temáticas discutidas em ciências sociais aplicadas, como socialização, identificação (e identidade) e noção de campo intelectual como campo de poder. Nesse sentido, segue-se com a discussão respondendo às questões inicialmente colocadas nesta seção por meio do conceito de socialização.

\section{Por que Ler os Clássicos e a Socialização: a estrutura CONSTITUINDO O SUJEITO QUE TAMBÉM SE CONSTITUI}

Segundo Berger e Luckmann (1985), a socialização primária é vivida na infância e a socialização secundária é qualquer processo posterior que introduza um indivíduo já socializado em novos setores do mundo objetivo de sua sociedade. Nesse sentido, em relação ao pesquisador, é possível afirmar que a escola (aplica-se aqui o termo escola como representativo de todas as instituições de ensino por qual o sujeito passa, seja na educação básica ou na própria academia, principal campo para análise da formação do pesquisador) está para a socialização secundária assim como a família está para a socialização primária.

Enfatizando o caráter histórico de contínuas socializações das quais os clássicos fazem parte, pode-se dizer que 
[...] os clássicos são aqueles livros que chegam até nós trazendo consigo as marcas das leituras que precederam a nossa e atrás de si os traços que deixaram na cultura ou nas culturas que atravessaram (ou mais simplesmente na linguagem ou nos costumes). (CALVINO, 1999, p. 10)

E a escola, nesse aspecto,

[...] deve fazer com que você conheça bem ou mal um certo número de clássicos dentre os quais (ou em relação aos quais) você poderá depois reconhecer os 'seus clássicos'. A escola é obrigada a dar-lhe instrumentos para efetuar uma opção: mas as escolhas que contam são aquelas que ocorrem fora e depois de cada escola. (CALVINO, 1999, p. 13, grifo nosso)

Observa-se que a escola e os clássicos que ela indica podem representar a ação da estrutura sobre o sujeito que virá a ser pesquisador ou já o é. Ou seja, ela tem um papel fundamental na socialização do pesquisador. Contudo, partindo de uma perspectiva na qual se considera a construção social da realidade (BERGER; LUCKMANN, 1985), ressalta-se que o sujeito não é apenas constituído pelas estruturas sociais, pois ele também se constitui enquanto pesquisador. Justamente por esse motivo, Calvino (1999, p. 13) enfatiza que as escolhas mais importantes são aquelas que ocorrem fora e depois da escola, e que "[...] é só nas leituras desinteressadas que pode acontecer deparar-se com aquele que se torna o 'seu' livro" (ainda que não se concorde com o "só" em sua frase).

Nesse sentido, as referências adquiridas pelo sujeito nos processos de socialização pelos quais passa orientam suas ações e escolhas, mas há um "eu" (ou vários "eus") que também decide $(\mathrm{m})$ quais são os "seus" clássicos. Assim, defende-se a formação de um pesquisador que seja sujeito ativo, constituído e constituinte, e que se utilize da crítica reflexiva para pensar os próprios clássicos, e que não seja simplesmente replicante. Ainda, que pense os clássicos considerando o contexto de análise utilizado por eles, bem como a adequação ou não ao contexto ao qual se deseja "aplicar" suas teorias.

A formação dos sujeitos pesquisadores em fase, diga-se, de socialização ocorre em seu cotidiano $e$ nas diversas relações que se estabelecem ao longo do processo. Não só a leitura dos clássicos, mas também o contato com professores, orientadores, colegas de estudo, entrevistados, sujeitos (e não objetos) de estudo contribuem para sua formação. Muitas vezes esta lhes é imposta pelo mainstream da área ou campo de pesquisa ou até mesmo por orientadores e professores, outras vezes trata-se de uma adesão pessoal do pesquisador a uma determinada corrente ou doutrina de pensamento, tornando-se assim um discípulo de seus mestres (professores, orientadores ou mesmo outros pesquisadores). Todavia, destaca-se a importância do posicionamento crítico do pesquisador diante de tais situações, de forma a evitar se tornar um mero replicante.

Nessa discussão, as relações entre socialização primária e socialização secundária precisam ser destacadas. As noções advindas da socialização primária continuam a exercer seu efeito nas socializações secundárias dos indivíduos, pois esquemas de referência são mantidos. Nesse processo, podem ocorrer até certas crises, nas quais os indivíduos percebem na socialização secundária aspectos que conflitam com as bases de referência que adquiriram na socialização primária (BERGER; LUCKMANN, 1985). O que pode gerar angústia ou, até mesmo, alterações nessas referências primárias, já que as socializações nem sempre são "perfeitas", "exatas", "precisas".

Ao se formar como pesquisador, a leitura dos clássicos se torna importante mesmo que seja uma releitura, pois há uma diferença entre as leituras que se faz na "maturidade" com as leituras que se faz na juventude. Ou seja, ao entrar na academia, é importante que eles sejam lidos ou, ainda, relidos.

[...] ler pela primeira vez um grande livro na idade madura é um prazer extraordinário: diferente (mas não se pode dizer maior ou menor) se comparado a uma leitura da juventude. A juventude comunica ao ato de ler como a qualquer outra experiência um sabor e uma importância particulares; ao passo que na maturidade apreciam-se (deveriam ser apreciados) muitos detalhes, níveis e significados a mais. (CALVINO, 1999, p. 10)

Dessa forma, é possível apreender no que se chama de maturidade detalhes mais específicos e mesmo visões mais abrangentes dos clássicos. Além disso, a capacidade de compreender as relações entre "o que já diziam os clássicos" e os fatos sociais contemporâneos pode ser aprimorada. 
Isso vale tanto para os clássicos antigos quanto para os modernos. Se leio a Odisseia, leio o texto de Homero, mas não posso esquecer tudo aquilo que as aventuras de Ulisses passaram a significar durante os séculos e não posso deixar de perguntar-me se tais significados estavam implícitos no texto ou se são incrustações, deformações ou dilatações. Lendo Kafka, não posso deixar de comprovar ou de rechaçar a legitimidade do adjetivo kafkiano, que costumamos ouvir a cada quinze minutos, aplicado dentro e fora de contexto. Se leio Pais e filhos de Turgueniev ou Os possuídos de Dostoievski não posso deixar de pensar em como essas personagens continuaram a reencarnar-se até nossos dias. (CALVINO, 1999, p. 11-12, grifo do autor)

Mas mesmo as leituras da juventude são importantes para a constituição do pesquisador, já que

[...] podem ser [...] formativas no sentido de que dão uma forma às experiências futuras, fornecendo modelos, recipientes, termos de comparação, esquemas de classificação, escalas de valores, paradigmas de beleza: todas, coisas que continuam a valer mesmo que nos recordemos pouco ou nada do livro lido na juventude. Relendo o livro na idade madura, acontece um reencontrar com aquelas constantes que já fazem parte de nossos mecanismos interiores $e$ cuja origem havíamos esquecido. Existe uma força particular da obra que consegue fazer-se esquecer enquanto tal, mas que deixa sua semente. [...] Os clássicos são livros que exercem uma influência particular quando se impõem como inesquecíveis e também quando se ocultam nas dobras da memória, mimetizando-se como inconsciente coletivo ou individual. (CALVINO, 1999, p. 10-11)

Assim, a influência que a leitura exerce sobre nós nos processos de socialização precisa ser destacada, aspecto no qual reside a importância de se ler os clássicos e não apenas os "leitores" desses clássicos. Pois estes leitores foram também socializados e se identificam ou não com os clássicos, de modo que suas percepções sobre eles terão um viés subjetivo. Há, pois, que se reconhecer não só a subjetividade do pesquisador que se constrói, como também a subjetividade dos autores que se lê.

Pode-se ressaltar ainda que nas várias "instâncias" de socialização por qual passa um pesquisador, como a graduação, o mestrado, o doutorado e outras formações complementares, ele pode vir a representar, como diria Raul Seixas (SEIXAS, 1973), "uma metamorfose ambulante". Mas não uma metamorfose no sentido em que se constrói e desconstrói como pesquisador da mesma forma que se troca uma roupa. Uma metamorfose que sugere que a(s) socialização(ões) do pesquisador leva a diferentes identificações do mesmo com autores e clássicos ao longo de sua trajetória. Por isso, então, se falará de identificação.

\section{Por que Ler os Clássicos e a IDENTIFICAÇÃO: A INFLUÊNCIA DA SUBJETIVIDADE DO SUJEITO PESQUISADOR}

O conceito de socialização possui relações com a noção de identificação, a qual julga-se ser também importante para pensar a relação entre os clássicos e a formação do pesquisador, noção essa que se relaciona também ao conceito de identidade. É por meio da socialização que o indivíduo constrói e reconstrói sua identidade (DUBAR, 2005; FERNANDES; MARQUES; CARRIERI, 2010), sendo ela fruto de sucessivas socializações (PAIVA; MELO, 2010). Além disso, os estudos sobre socialização se integram a movimentos teóricos que se debruçaram sobre a construção da identidade, defendendo o papel ativo do indivíduo nessa construção. (FERNANDES; MARQUES; CARRIERI, 2010)

Os processos de construção da identidade podem ocorrer por identificação, o que "[...] remete ao alinhamento do universo simbólico do plano individual em relação ao social [...]" (PIMENTEL; CARRIERI, 2011, p. 2) e também por socialização, "[...] que se refere ao processo de transmissão de regras e normas de condutas tidas como socialmente aceitas por um dado grupo social a um indivíduo". (BERGER; LUCKMANN, 2004 apud PIMENTEL; CARRIERI, 2011, p. 2)

Além disso, as relações entre identificação $e$ socialização com a noção de identidade podem ser encontradas em contribuições de estudos da psicologia e da sociologia, por meio das quais é possível observar

[...] dois processos complementares de construção de identidade: de um lado, as correntes da psicologia contribuem com a noção de identificação, como um processo eminentemente subjetivo, que se origina do sujeito 
em relação ao Outro (ou Outros) que lhe são significativos (ERIKSON, 1976); de outro, as diferentes correntes das ciências sociais identificam a existência de um processo denominado 'socialização', que faria justamente o caminho inverso da identificação - ou seja, ele seria constituído pela transmissão de determinados tipos de comportamentos, valores e normas socialmente aceitas e tidas como corretas por um determinado grupo social para um indivíduo ou um grupo (BERGER; LUCKMANN, 2004 apud PIMENTEL; CARRIERI, 2011, p. 8)

Embora se fale neste trabalho do conceito de identidade, o conceito que se adota como central para a discussão é o de identificação (que é entendida como um processo contínuo de construção, de acordo com Fernandes, Marques e Carrieri (2010)), pois acredita-se que a identidade não é algo acabado, não é fixa, ela está sendo continuamente formada. Mesmo entre os autores que não acreditam que a mesma seja fixa, ela pode ser interpretada como múltipla, fluida ou autônoma (CARRIERI; PAES DE PAULA; DAVEL, 2008). Dessa forma, corrobora-se com Hall (2006) em sua defesa de que ao invés de falar de identidade, dever-se-ia falar de identificação. Assim, se estaria vendo a identidade não como algo acabado, mas sim como algo em processo. Nesse sentido, quando cita-se aqui a identidade, que é utilizada no sentido de algo em construção, não sendo fixa e nem acabada.

A identificação é um conceito importante para a reflexão a respeito da importância de se ler os clássicos porque é por meio de um processo de identificação ou não com grupos de autores, escolas teóricas, paradigmas, ontologias, epistemologias, que o sujeito se constrói enquanto pesquisador, que sua identidade é construída. A partir de 1979, inicia-se o conceito de teoria social da identidade, sendo que sua concepção básica é a de que "[...] todo ser humano faz parte de vários grupos e se envolve em múltiplas identificações, possuindo um repertório de categorias sociais". (FERNANDES; MARQUES; CARRIERI, 2010, p. 37)

Nesse sentido, prioriza-se a noção de que a identidade pessoal é uma condição que resulta da interação do indivíduo com a realidade (ARCHER, 2000). Na temática aqui discutida, a realidade seria o contato do sujeito com a academia, permeado não só por relações e interações sociais, como também por interações com os clássicos cujas vozes se cristalizam em obras literárias.

\begin{abstract}
Identidade é uma palavra originária da lógica, álgebra e filosofia clássica, que se estendeu por diferentes campos científicos e escolas de pensamento, ganhando novos significados. Derivada dos vocábulos latinos idem e identitas, que significam 'o mesmo', e entitas, que significa 'entidade' (CALDAS; WOOD JR., 1997), [...] a referência à identidade na literatura é cercada de várias conotações e sinônimos tais como: oneself (si mesmo), self, ego, self-perception (autopercepção), self-definition (autodefinição), self-conception (autoconcepção), autoimagem, autorrepresentação, autoconsciência (HOGG; TERRY, 2000; SILVA, 2002 apud FERNANDES; MARQUES; CARRIERI, 2010, p. 29-30).
\end{abstract}

Para Berger e Luckmann (1974, p. 228),

A identidade é [...] um elemento-chave da realidade subjetiva, e tal como toda realidade subjetiva, acha-se em relação dialética com a sociedade. A identidade é formada por processos sociais. Uma vez cristalizada, é mantida, modificada ou mesmo remodelada pelas relações sociais. Os processos sociais implicados na formação e conservação da identidade são determinados pela estrutura social. Inversamente, as identidades produzidas pela interação do organismo, da consciência individual e da estrutura social reagem sobre a estrutura social dada, mantendo-a, modificando-a ou mesmo remodelando-a.

O conceito de identidade é múltiplo, e há uma "[...] complexidade que se encontra imbricada em suas manifestações empíricas" (PIMENTA; LOPES; CORRÊA, 2010, p. 63). Como ressalta Freitas (2010), a identidade é um daqueles temas "[...] impossíveis de serem debatidos e analisados em toda sua complexidade, [...] falar do sentimento de identidade parece ser um caminho mais fácil" (FREITAS, 2010). Assim, quando se fala aqui dos processos de identificação dos sujeitos com os clássicos que lê, fala-se também do sentimento que está relacionado a esse processo de identificação, principalmente relativo ao modo como o indivíduo se percebe, e julga tanto como ele e o clássico são percebidos.

Os estudos dos processos de identificação social podem ser sustentados por meio de teorias como as 
da identidade social e a da categorização do self (FERNANDES; MARQUES; CARRIERI, 2009), sendo que a teoria da identidade social contribui para a compreensão do modo como o indivíduo usa categorias sociais para se classificar e classificar os outros. (NKOMO; COX JR., 1999)

Fernandes, Marques e Carrieri (2009) afirmam que autores da teoria da identidade social e da categorização do self consideram três componentes no processo de identificação do sujeito com as categorias e grupos sociais: os componentes cognitivo, afetivo e valorativo.

O componente cognitivo diz respeito à autocategorização e à autodefinição do sujeito. Isto é, ao estabelecer um senso de pertencimento a determinado grupo ou categoria social, a pessoa pode assumir seus protótipos e estereótipos, os quais expressam padrões e atributos que caracterizam e distinguem o grupo dos demais. [...] O componente afetivo, incorporado ao componente cognitivo do processo de identificação, é retratado pelos sentimentos do sujeito em relação ao fato de pertencer a um determinado grupo social. [...] O componente valorativo é vinculado à forma como, na percepção da pessoa, seu grupo social é valorizado pelos outros grupos. (FERNANDES; MARQUES; CARRIERI, 2009, p. 689-691)

Nesse processo, os sujeitos podem se identificar ou não com os clássicos que lêem, o que influencia o pesquisador que será (ou que continuará ou não a ser). Para falar da relação da formação da identificação com a leitura dos clássicos, é importante adicionar um pronome possessivo antes do substantivo clássico. Há o meu clássico, o seu clássico, o nosso clássico, o clássico deles, e daí em diante. Considera-se importante enfatizar que não há, necessariamente, clássicos unânimes para todos os pesquisadores, nem para todas as áreas de conhecimento. Os clássicos tendem a ser, na verdade, aqueles que são tratados pela maioria como tal. Até porque o indivíduo pode manter, relativamente à coletividade, uma identidade legitimadora ou uma identidade de resistência (CASTELLS, 2000), a qual seria sustentada por bases advindas de escritores marginalizados.

Importante destacar também que um autor marginalizado "hoje" pode ser um clássico em algum contexto "amanhã", o que aconteceu com vários autores, dentre os quais é possível citar, no cenário brasileiro das ciências sociais, Alberto Guerreiro Ramos (1915-1982), cuja noção de racionalidade substantiva (RAMOS, 1989) não era muito aceita em sua época, sendo atualmente um consagrado sociólogo (JUNIOR, 2010), tendo sido, por exemplo, recentemente homenageado com uma edição especial em um periódico da área de Organizações: O\&S (Organizações \& Sociedade) (O\&S, 2010). Nesse sentido, o clássico para o indivíduo pode ser tanto aquele legitimado na sociedade, quanto um autor marginalizado, mas com quem o indivíduo se identifica.

Assim, o sujeito, no exercício de sua capacidade de ação e de sua subjetividade, pode não se identificar com algum autor ou obra considerados clássicos. Mesmo esse "não se identificar" faz parte da construção de sua identidade como pesquisador. A identificação com o clássico estaria ainda relacionada a um sentimento de pertencimento a determinado grupo (TAJFEL, 1978), neste caso, o grupo dos leitores e adeptos das ideias desse clássico.

Nesse processo, o sujeito pode objetivar saber "quem é ele" enquanto pesquisador. Importa que "[...] o seu clássico é aquele que não pode ser-lhe indiferente e que serve para definir a você próprio em relação e talvez em contraste com ele" (CALVINO, 1999, p. 13, grifo do autor). Identifica-se ou não com determinados grupos sociais, sendo que há aqueles grupos que serão chamados de nossos. O pesquisador pode ou não se identificar com os que são chamados de clássicos, com suas bases ontológicas, epistemológicas, metodológicas, com os temas que trabalha, e até mesmo com sua própria forma de escrita. Nesse processo de identificação que, ressalta-se, é contínuo, o sujeito vai se construindo como pesquisador.

Sendo contínuo, o sujeito pode inventar ou reinventar o pesquisador que é, se identificando e (des) identificando ("toda releitura de um clássico é uma leitura de descoberta como a primeira" (CALVINO, 1999, p. 13, grifo do autor). Ou até mesmo pode não se identificar com "nada" que seja considerado clássico. Porém, para essa mesma não identificação, é preciso, antes, lê-los, um ler que implica em conhecê-los. Mas não um conhecer absoluto, necessariamente "verdadeiro", que corresponda ao modo como a academia considera esse clássico ou à própria descrição que esse clássico faça de si. É um conhecer influenciado pela subjetividade desse sujeito leitor, que é pesquisador ou futuro pesquisador. 
Nesse contínuo processo, a identidade é, portanto, "[...] percebida como um construto [...] passageiro e sujeito às contingências temporais" (SARAIVA et al., 2010, p. 18). Por exemplo, é possível considerar as divisões temporais que se faz em relação à formação de um pesquisador, como o mestrado e o doutorado, nas quais pode haver um contínuo processo de formação da identidade do sujeito-pesquisador. Um clássico com o qual se identifica hoje pode ser um clássico questionado amanhã.

A interação que existe entre identidade $e$ ambiente leva ao próprio processo de construção e reconstrução de identidades (SARAIVA et al., 2010). Sendo assim, a identidade é como uma metamorfose, pois os indivíduos vão se transformando ao longo de sua trajetória (CIAMPA, 2001), aqui acadêmica. O indivíduo é construído e se constrói como pesquisador não só quando lê, mas também e significativamente quando interage com os outros sujeitos de seu campo. Pois a categorização social externa é importante na construção da identidade. O indivíduo considera o que os outros pensam dele (SARAIVA et al., 2010). A identidade não é só para si, é também uma identidade para o outro (DUBAR, 2005; FERNANDES; MARQUES; CARRIERI, 2010), o que o outro diz a respeito de um clássico com o qual se identifica pode influenciar na própria percepção que se tem de "seu" clássico. Pois o indivíduo pode concordar ou recusar as identificações que recebe dos outros indivíduos ou grupos. (DUBAR, 2005)

Um exemplo que se julga importante é uma experiência pessoal de dois dos próprios autores deste ensaio teórico que, em determinado momento de "socialização secundária" em pós-graduação, observaram seus colegas de curso descrevendo como passam por uma crise de identidade por estarem cursando uma disciplina que questiona muito dos "valores acadêmicos" que até então preconizavam. O processo de socialização pelo qual passavam questionava e via com certa desconfiança princípios que até então estavam incorporados por esses indivíduos, que se tornaram verdadeiros habitüs ${ }^{2}$ desses pesquisadores.

Há uma diferenciação em relação à identidade pessoal e à identidade social. A pessoal é uma espécie de "[...] construção individual do conceito de si e a social, o conceito de si a partir da vinculação da pessoa a grupos sociais" (MACHADO; KOPITTKE, 2002, p. 2).
Assim, o clássico para o indivíduo pode ser legitimado como tal ou não. A contradição também pode estar presente na relação com o clássico, pois mesmo que o indivíduo não se identifique com ele, isso não implica necessariamente que ele o "descarte". Nesse sentido, Calvino dá um exemplo de sua relação com o filósofo e teórico político Rousseau:

Tudo aquilo que Jean-Jacques Rousseau pensa e faz me agrada, mas tudo me inspira um irresistível desejo de contradizê-lo, de criticá-lo, de brigar com ele. Aí pesa a sua antipatia particular num plano temperamental, mas por isso seria melhor que o deixasse de lado; contudo não posso deixar de incluí-lo entre os meus autores (CALVINO, 1999, p. 13).

Pode-se dizer que há uma "[...] multiplicidade de identidades que conviveriam simultaneamente, em harmonia ou conflito" (FERNANDES; MARQUES; CARRIERI, 2010, grifo dos autores). Calvino admite não concordar com o que Rousseau diz, mas ao mesmo tempo não deixa de incluí-lo entre seus autores, pois se identifica com o mesmo, ainda que no desejo de contradizê-lo. A própria identidade é um elemento contraditório se pensar nela de uma forma dialética, como fazem Pimenta, Lopes e Corrêa (2010). As autoras ressaltam que a identidade é algo a ser expresso e suprimido ao mesmo tempo, sendo continuamente inventada. Ela é simultaneamente o exterior internalizado no sujeito e o interior externalizado por meio de suas ações (HALL, 1997). Ora o sujeito pode se identificar, ora não.

Há um interessante exemplo acadêmico a ser utilizado para a discussão, que é o ensaio teórico de Carrieri, Paes de Paula e Davel (2008) a respeito de identidade nas organizações, intitulado: "Identidade nas Organizações: Múltipla? Fluida? Autônoma?”. Pela abordagem que realizam em conjunto sobre identidade, é possível observar como as próprias identidades dos três pesquisadores (que são influenciadas pelos processos de identificação com clássicos, por exemplo) os levam a considerar de forma diferenciada o conceito (não se quer aqui estabelecer rótulos a esses pesquisadores, mas apenas demonstrar visões diferentes de mundo com os quais se identificam, e que influenciam sua abordagem). A identidade como múltipla viria de uma identificação de Carrieri com uma visão pós-estruturalista de mundo; a identidade como fluida, 
uma identificação de Davel com o pós-modernismo; e a identidade como autônoma, a visão de Paes de Paula, que se identifica com a Escola de Frankfurt. As identificações desses autores, diferenciadas, levam a diferentes adjetivações ao próprio conceito de identidade.

Reconhecida a importância dos clássicos devido aos processos de socialização do ser-pesquisador, será discutido a seguir o perigo dos apuds para estudar os clássicos. Porque o campo intelectual pode também ser visto como um campo de poder. Sendo assim, o pesquisador, no exercício de sua capacidade de escolha, pode também relacionar seus escritos a objetivos de lucro simbólico no campo em que atuam. Dessa forma, como ler de forma confiada leitores de clássicos? Afinal, eles não são sujeitos desinteressados no campo.

\section{Perigo dos "APUds": POR qUe LER OS CLÁSSICOS E A ABORDAGEM BOURDIEUSIANA ${ }^{3}$ DO CAMPO INTELECTUAL - O SER PESQUISADOR COMO SER POLÍTICO}

Nesse momento, parte-se de uma abordagem mais compreensiva acerca da importância dos clássicos por intermédio dos conceitos de socialização e identificação para uma abordagem que revela o caráter não desinteressado das ações e das escritas no âmbito acadêmico, indo ao encontro de uma dimensão mais política de análise da temática com o auxílio da abordagem de Bourdieu (2003; 2004; 2006) sobre os campos intelectual, científico e acadêmico. Nessa discussão, será defendida a importância de se ler diretamente os clássicos, evitando citações de citações (a utilizada expressão apud).

Uma expressão categórica que se pode utilizar para introduzir a discussão é que toda posição estética implica em uma posição política, segundo Bourdieu (2006). As práticas científicas, para Bourdieu (2003, p. 113), não são desinteressadas, apenas o são “[...] quando referidas a interesses diferentes, produzidos e exigidos por outros campos". O universo da ciência, para o autor, é um campo permeado por relações de força, lutas, estratégias e interesses. O poder conferido à palavra na forma de publicações científicas, por exemplo, precisa ser levado em consideração, pois ele pode influenciar vários outros acadêmicos iniciantes no campo (não só os iniciantes). A analogia que Bourdieu (2004) faz em relação ao campo de lutas como um jogo reforça a intensidade das disputas no campo:

A diferença maior entre um campo e um jogo [...] é que o campo é um jogo no qual as regras do jogo estão elas próprias postas em jogo (como se vê todas as vezes que uma revolução simbólica [...] vem redefinir as próprias condições de acesso ao jogo, isto é, as propriedades que aí funcionam como capital e dão poder sobre o jogo e sobre os outros jogadores). (BOURDIEU, 2004, p. 29)

Sendo assim, os pesquisadores, conscientes de sua posição política e da possível influência de suas palavras, sabem que, dependendo de sua posição no campo, podem influenciar a própria redefinição das regras do jogo. Nesse sentido, é importante considerar não só o ser político que é o próprio pesquisador, como também os próprios clássicos e aqueles que os estudam. É preciso, pois, romper com uma imagem de concorrência pura e perfeita das ideias no campo intelectual. (BOURDIEU, 2003)

Os pesquisadores e os escritores são, dessa forma, jogadores no campo, cujos interesses estão na acumulação de capitais que nele são importantes. Os próprios temas de pesquisa com que se trabalha são reflexos do ser político que é o pesquisador ou o intelectual. Pois o que se faz deve ser interessante não só para si mesmo, mas também para os outros (BOURDIEU, 2003). Além disso, há

[...] efeitos de sistemas de fatores que determinam as práticas e as ideologias de todo escritor na medida em que pertence a um campo intelectual dotado de uma estrutura determinada, por sua vez incluído em um campo do poder dotado de uma estrutura determinada. (BOURDIEU, 2006, p. 188)

Ou seja, para Bourdieu (1998), todo campo social, assim como o intelectual e o científico, se insere em um campo de poder. Dessa forma, considera-se a não neutralidade dos autores que se lê. Sua posição sobre determinado autor ou obra clássica será influenciada também por sua posição no campo e por seus interesses nele. Sendo assim, ler os clássicos é importante, já que cada autor interpreta sob seu ponto de vista e interesse determinado clássico. 
Estudar um clássico por intermédio de outro leitor é, sem dúvida, importante. Muitas vezes, interpretações alheias podem ajudar a compreender aspectos que não haviam recebido atenção ou que nem mesmo foram entendidos. Contudo, a não neutralidade e a subjetividade do que se lê influencia não somente na percepção que se tem sobre as ideias e os argumentos do clássico (o que advém do próprio processo de socialização $e$ de identificação), mas também nos interesses em jogo na sua escrita.

Se o próprio clássico possui sua tomada de posição política ao escrever, o que dizer então de uma interpretação ou apropriação política de um pesquisador a respeito do que diz esse clássico? O caráter indireto e secundário da obra do leitor de um clássico nem sempre irá refletir aquilo que o clássico quis (ou não quis) dizer. Pode-se fazer aí uma analogia com a brincadeira infantil do telefone sem fio ${ }^{4}$, pois o viés da interpretação de um clássico é triplamente determinado: pela subjetividade do escritor, pelos habitus que ele incorpora em seus processos de socialização e de construção da identidade, e pelo seu próprio interesse no campo. Como ressalta o próprio Calvino, muitas vezes descobre-se que um clássico muito comentado e famoso é totalmente diverso do que se pensava. (CALVINO, 1999)

A leitura de um clássico deve oferecer-nos alguma surpresa em relação à imagem que dele tínhamos. Por isso, nunca será demais recomendar a leitura direta dos textos originais, evitando o mais possível bibliografia crítica, comentários, interpretações. A escola e a universidade deveriam servir para fazer entender que nenhum livro que fala de outro livro diz mais sobre o livro em questão; mas fazem de tudo para que se acredite no contrário. Existe uma inversão de valores muito difundida segundo a qual a introdução, o instrumental crítico, a bibliografia são usados como cortina de fumaça para esconder aquilo que o texto tem a dizer e que só pode dizer se o deixarmos falar sem intermediários que pretendam saber mais do que ele. (CALVINO, 1999, p. 12)

Nesse sentido, citar sem ler o clássico é algo arriscado, o que muitas vezes ocorre, para o que corrobora Calvino (1999), que afirma que algumas obras são mais citadas do que lidas. Se "[...] um clássico é um livro que nunca terminou de dizer aquilo que tinha para dizer
[...]" (CALVINO, 1999, p. 11), como sugere o autor, quantas aberturas então não se realizam para várias interpretações e para aqueles que pretendem dizer o que não foi dito?

Um interessante exemplo são as interpretações diversas que se faz da obra de Karl Marx, intelectual alemão que é considerado um clássico (será que o clássico dispensa apresentação? Em tese, dispensaria, mas isso não ocorre, já que nem todos conhecem ainda quais são os clássicos de sua área, pode-se estar ainda em processo de socialização. Também, leitores de diferentes áreas podem ler o ensaio). Chasin (1995), por exemplo, critica a interpretação que Kautsky ${ }^{5}$ faz sobre a obra de Marx, o que se observa nos trechos a seguir:

- "por certo, das mais antigas e falsas é a versão kautskyana" (CHASIN, 1995, p. 340);

- "e que por gerações serviu de referência ou paradigma" (CHASIN, 1995, p. 340-341);

- "em seu explícito naturalismo positivista, a um tempo ingênuo e grosseiro, Kautsky resume o mérito científico de Marx em ter..." (CHASIN, 1995, p. 341);

- e "é sob o contorno desse deplorável aparato teórico, escandalosamente incompatível com o pensamento de Marx... (CHASIN, 1995, p. 341).

Duas análises podem ser feitas nesse exemplo. O risco de se ler Kautsky, e também o risco de ler Chasin (1995), pois ele também possui interesses no campo ao criticar Kautsky (não se entrará aqui na discussão se as críticas são ou não plausíveis).

Ler diretamente o clássico é também importante por descobrir aquele que "primeiro" formulou determinadas ideias e pensou sobre determinadas questões.

O clássico não necessariamente nos ensina algo que não sabíamos; às vezes descobrimos nele algo que sempre soubéramos (ou acreditávamos saber), mas desconhecíamos que ele o dissera primeiro (ou que de algum modo se liga a ele de maneira particular). E mesmo esta é uma surpresa que dá muita satisfação, como sempre dá a descoberta de uma origem, de uma relação, de uma pertinência. [...] Os clássicos são livros que, quanto mais pensamos conhecer por ouvir dizer, quando são lidos de fato mais se revelam novos, inesperados, inéditos. Naturalmente isso ocorre quando um clássico 'funciona' como 
tal, isto é, estabelece uma relação pessoal com quem o lê (CALVINO, 1999, p. 12)

Outra questão interessante a ser enfatizada é que não basta ler os clássicos, é importante também que se leiam boas traduções desses clássicos, pois essas são ferramentas passíveis de utilização política, podendo ser influenciadas pelos interesses do tradutor e dos outros para quem escreve dentro do campo. Sendo assim, podem se tornar verdadeiras armadilhas para o sujeito que se constrói pesquisador.

É possível analisar aqui o exemplo de traduções da obra "Ética protestante e o espírito do capitalismo" de Max Weber, em que obra e autor são considerados clássicos (lembrem-se, não necessariamente, o meu clássico ou o seu clássico). Weber é um intelectual alemão cuja obra influenciou a Sociologia principalmente, mas também a Economia, a Ciência Política, o Direito, a Filosofia e a Administração. Optou-se por demonstrar traduções dessa obra especificamente porque ela foi eleita o mais importante escrito teórico publicado no século XX por intelectuais convidados pelo jornal brasileiro Folha de São Paulo'.

É possível observar no Quadro 1 um mesmo trecho deste livro, mas em duas diferentes traduções.

\section{Traduçāo da Editora Cengage Learning - Sāo Panlo \\ O tipo ideal de enpreendeder capitalista, cemo era representado, mesme na Alemanha, por destacados exemples ecasionaks, não mantém redacào nenhuma com estes arrivistas mais on menos refinadox. Ele evita a costentaçăo $e$ as despesas desnecessánias, assim como gozo consciente de seu poder, e envergonha-se com os sinuis de reconhedimento sodill que recebe. Em outras palavras, seu modo de vida distingue-se, frequentemente, e teremos que investigar o significado histórico deste importante fato, per uma certa tendencia ascética como aparece de modo bastante claro na "pregagĩo de Franklin antes citada.}

\section{Traduçāo da Editors Schwarcz - Sāo Pauko}

O tipo ideal do empresirie capitalista, tal come representado entre nós slemäes haja vista alguns exemplo eminentes, nầo tem nenhum parentesco con esses ricaços de aparênda mats óbvia ou refinada, tanto faz. Ele se esquiva à costentação $\mathrm{e}$ à despesa inútil, bem como ao goro consciente do seu poder, e sente se antes incomedado com os sinais externos da deferencia sodial de que desfruta Su conduta de vida, noutras palavras, comperta quase sempre certo lance asctice, tal como veio à luz com clareza no citado "sermino" de Franklin... (Weber, 2004: 62)

Quadro 1: Diferentes traduções de trecho da obra Ética Protestante e o Espírito do Capitalismo de Max Weber Fonte: Elaborado pelos autores com base em Weber (2004; 2009)

É possível observar que, nos dois trechos, traduções de palavras que podem implicar em interpretações diferentes do que Weber quis ou não dizer (Quadro 2).

Observa-se o risco não só de não se ler o clássico, como também de se ler traduções que possam estar equivocadas. Mesmo eliminando as possibilidades de interesses do tradutor no campo, sua própria subjetividade também influencia no modo como traduzirá o clássico. Ademais, ele possui identidade diferente do outro tradutor e, ainda, passou por processos de socialização diferentes. Mesmo que tivessem estudado na mesma escola, sua história e socialização primária não foram as mesmas. Recomenda-se então não só a leitura dos clássicos, mas que se escolham cuidadosamente suas traduções.
Quando se discute o aspecto das traduções, volta-se novamente à discussão sobre o risco do anacronismo conceitual. Como ressalta Cunha (2013, p. 153),

[...] é por vezes confrangedor ver algumas traduções literarizantes de clássicos, que retiram às expressões originais toda a carga original, $e$ as atualizam normalmente, com evidente anacronismo conceitual e institucional.

Mas como escolher cuidadosamente traduções? Não é nossa intenção aqui elaborar uma receita, uma prescrição de como se escolher boas traduções. Mas é possível apontar alguns aspectos que merecem atenção. Em primeiro lugar, um resgate histórico sobre o clássico, a obra e seu contexto de produção deveria ser realizado 


\begin{tabular}{|c|c|c|}
\hline $\begin{array}{l}\text { Tradugîo da Fditora } \\
\text { Cengage Learning - Sāo } \\
\text { Paulo }\end{array}$ & $\begin{array}{l}\text { Traduplo da } \\
\text { Editors Schwarez } \\
\text { - Sto Paulo }\end{array}$ & Comentírios \\
\hline Emprecendedor & Empresírio & $\begin{array}{l}\text { Hil virios conceitos de emproendedor, que poden } \\
\text { diferir do que seria un simples emprestirio. }\end{array}$ \\
\hline $\begin{array}{l}\text { tal como era } \\
\text { representado, mesme na } \\
\text { Alemanha }\end{array}$ & $\begin{array}{l}\text { tal como } \\
\text { representado por } \\
\text { nós alemaies }\end{array}$ & $\begin{array}{l}\text { O advérbio mesme, tal como apheado ma primeira } \\
\text { tradochâ, indica que a representagio ma Alemanha } \\
\text { algo fora do convencional ou que há cutros lugares en } \\
\text { que isso se aplica de forma mais contundente, ou ainda } \\
\text { que na Alemanha houvesse condiçöes que } \\
\text { dificultassem essa representapila. }\end{array}$ \\
\hline exemplos ocasionais & $\begin{array}{l}\text { Exemplos } \\
\text { eminentes }\end{array}$ & $\begin{array}{l}\text { - Significado de ocasional: que acontece por acaso, } \\
\text { eventual, acidental (PRIBERAM, 2011). } \\
\text { - Significado de eminente: Notível, ixstre, alto, } \\
\text { elevado (PRIBERAM, 2011). }\end{array}$ \\
\hline $\begin{array}{l}\text { com estes arrivistas } \\
\text { muils ou menos } \\
\text { refinades }\end{array}$ & $\begin{array}{l}\text { com esses ricapos } \\
\text { de aparécia } \\
\text { mais bbvia ou } \\
\text { refinada, tanto } \\
\text { fax }\end{array}$ & 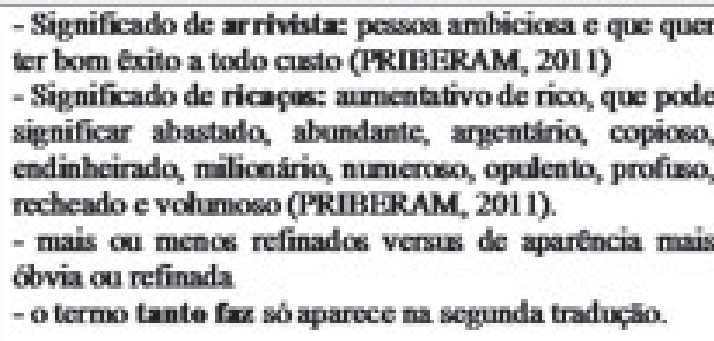 \\
\hline $\begin{array}{l}\text { e envergonha-se com } 06 \\
\text { sinais } \\
\text { reconhecimento social } \\
\text { que recebe }\end{array}$ & $\begin{array}{l}\text { e sente-se antes } \\
\text { incoenodado oom } \\
\text { os sinais externos } \\
\text { da deferencia } \\
\text { social de que } \\
\text { desfrata }\end{array}$ & $\begin{array}{l}\text { Consideramos que receber algo nilo implica } \\
\text { nocessariamente em que o roceptor desfrute do que } \\
\text { recebeu. }\end{array}$ \\
\hline $\begin{array}{l}\text { e teremos que investigar } \\
\text { o significado histórico } \\
\text { deste inportante fato }\end{array}$ & $\begin{array}{l}\text { (nāo há essa } \\
\text { observaçấo) }\end{array}$ & $\begin{array}{l}\text { Comentíio que seria importante, mas que aparece } \\
\text { apenas na primeira traduplio. }\end{array}$ \\
\hline $\begin{array}{l}\text { por uma certa tendência } \\
\text { ascética }\end{array}$ & $\begin{array}{l}\text { cemperta quase } \\
\text { sempre certo } \\
\text { lance ascético }\end{array}$ & 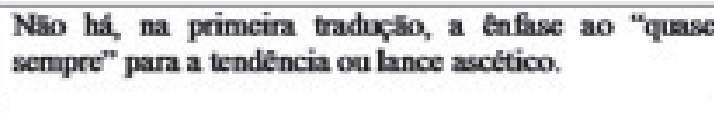 \\
\hline
\end{tabular}

Quadro 2: Comparações entre duas traduções de trecho da obra Ética Protestante e o Espírito do Capitalismo de Max Weber

Fonte: Elaborado pelos autores com base em Weber (2004; 2009)

previamente à leitura seja de um original ou de uma tradução. Munidos de um melhor conhecimento contextual, ou de um melhor entendimento das condições sociais de produção dos discursos presentes na obra a ser lida, pode-se amenizar as possíveis discrepâncias relativas tanto ao anacronismo conceitual quanto às próprias características e interesses dos tradutores.

Em segundo lugar, a tradução deve ser considerada como um "[...] processo de criação em que o tradutor é um servidor da verdade do autor e suporte da alteridade deste. Não se trata, pois, de fidelidade ao texto, mas de lealdade ao homem que se faz presente no texto" (PRESTES, 2010, p. 11). Nesse sentido, recomenda-se que se pense quem é o tradutor, quais são suas qualificações e experiências, e que se considere seu nível de conhecimento a respeito do clássico que traduz. Esse aspecto não elimina a subjetividade de sua tradução. No entanto, nos possibilita ter mais acesso à referida lealdade.

O terceiro aspecto importante a ser considerado na escolha da tradução é a editora, seu perfil de atuação, estilo de tradução e experiência com obras literárias de clássicos. A tradução é um processo coletivo que não compete apenas ao tradutor. Como argumenta Prestes (2010, p. 78-79), 
Às vezes, a decisão por certas opções não é do tradutor e sim das editoras. Por mais que o tradutor tome a decisão de respeitar o original, mesmo que não fique um texto belo, em português, as normas de redação das editoras - essa verdadeira camisa-de-força que não tem outra função senão a de deixar os textos aparentemente mais bonitos - falam, na maioria das vezes, mais alto do que a simplicidade do desejo de transcendê-las. Por isso, determinadas construções textuais que deformam, de certo modo, o estilo do autor e ignoram sua alteridade podem estar nas traduções, mas não por opção do tradutor. Por mais que o tradutor consiga estabelecer o dialogo genuíno com o autor, sem medir esforços para que o autor esteja presente na tradução, algumas editoras, com atitudes autoritárias, anulam não só a alteridade do autor, mas também a do tradutor.

Nesse processo de escolha, que envolve então vários aspectos, buscar a indicação de estudiosos e pesquisadores de determinados clássicos a respeito das melhores traduções, quando não se tem acesso a mais informações, pode ser uma boa saída. $\mathrm{O}$ ideal ainda é que esses estudiosos ouvidos sejam conhecedores da língua original do clássico, a fim de que tenha parâmetros mais consolidados para a indicação de uma boa tradução.

Por fim, a Figura 1 demonstra uma síntese de algumas das ideias discutidas no ensaio relativamente aos conceitos de socialização, identificação (e identidade) e campo intelectual como campo de poder.

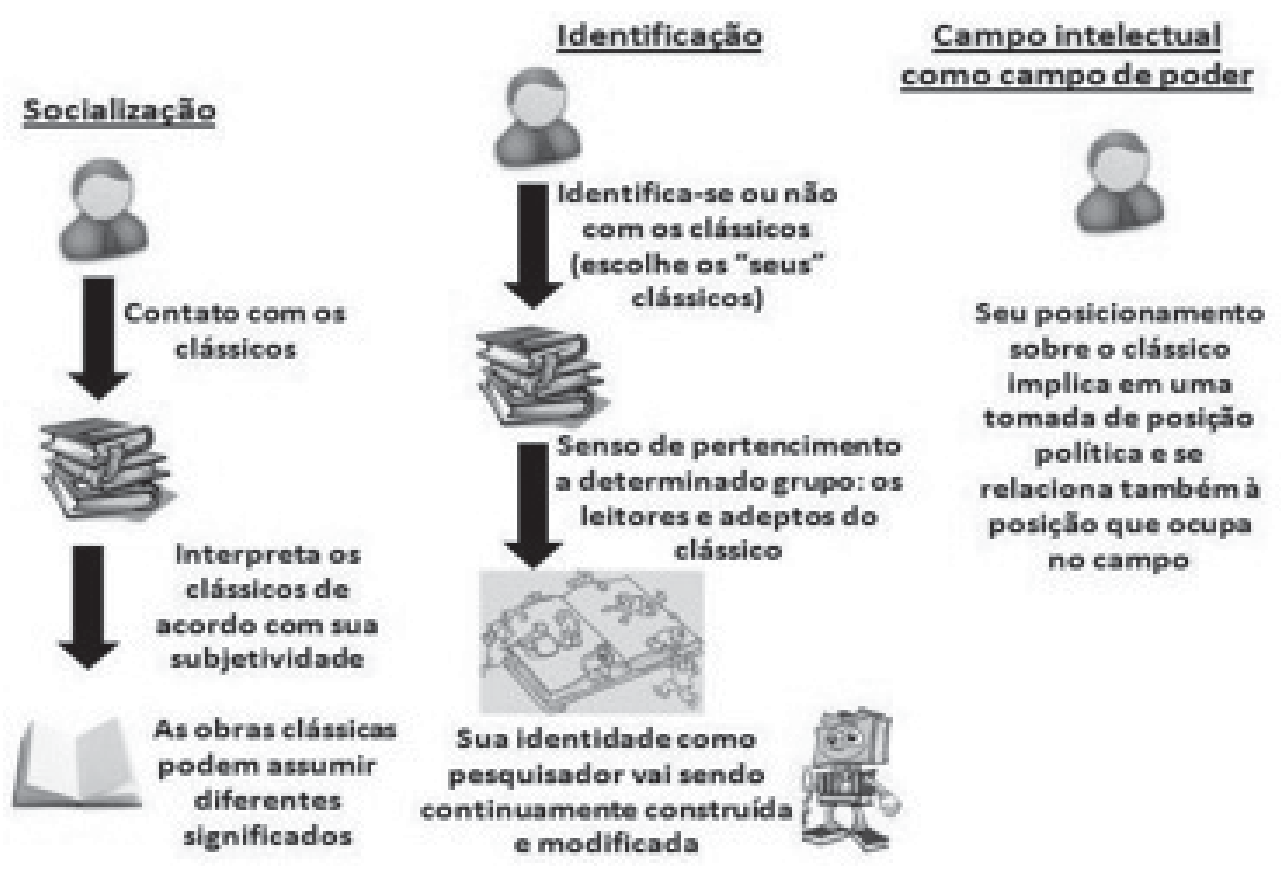

Figura 1: Síntese de algumas das ideias do ensaio teórico

Fonte: Elaborado pelos autores deste artigo

A síntese presente na Figura 1 permite enfatizar que, ao longo da discussão, analisa-se como, por intermédio da socialização, a estrutura constitui o sujeito que também se constitui (a ele são apresentados alguns clássicos em seu processo de socialização, os quais podem ser interpretados de maneiras diversas por meio de sua subjetividade). Pelo conceito de identificação, percebe-se a influência da subjetividade do sujeito pesquisador ao se identificar ou não com os clássicos, escolhendo aqueles que serão os "seus" clássicos. E, por meio da noção de campo intelectual como campo de poder, defende-se o perigo dos apuds e da leitura de traduções descuidadas ou muito interessadas dos clássicos. Parte-se então para algumas considerações finais do ensaio. 


\section{Enfim, Leiam os Clássicos}

Neste ensaio, procurou-se extrapolar o simples desenrolar de motivos para que se leiam os clássicos. Pretendeu-se associá-los à sua importância para a formação do pesquisador, cujas pesquisas podem impactar não só a teoria de seu campo, como a própria sociedade. Não se teve a pretensão no ensaio, como ressalta Calvino (1999, p. 16), que "[...] se pense que os clássicos devem ser lidos porque 'servem' para qualquer coisa. [que] A única razão que se pode apresentar é que ler os clássicos é melhor do que não ler os clássicos".

Uma questão que poderia ser formulada de forma a consolidar alguns dos principais aspectos discutidos ao longo deste ensaio é: os clássicos são obras "obrigatórias de outrora" ou "fundamentais para agora"? Espera-se que a esta altura a resposta pareça clara para a maioria de nossos leitores, já que os clássicos são as duas coisas, pois como nunca terminam de dizer o que pretendiam, são tão fundamentais agora quanto obrigatórios outrora, especialmente no âmbito acadêmico, ambiente em que conhecer os clássicos é fundamental tanto para a socialização quanto para a legitimação do pesquisador no campo.

Outro aspecto que deve ser ressaltado é o próprio viés dos autores deste ensaio, no sentido em que se tentou estabelecer uma discussão da importância dos clássicos de modo indistinto para todas as áreas do conhecimento (os clássicos são importantes para as diversas áreas), mas sem dúvida houve influência da nossa formação. Como nossa socialização secundária está na área de Ciências Sociais Aplicadas, especificamente Administração, os exemplos que aqui foram utilizados de clássicos possuem o viés de tal formação. Dessa forma, chamou-se novamente atenção para o fato de que, como sujeitos, e não simples "marionetes" da estrutura, nossa subjetividade se insere na escolha dos clássicos que ocasionalmente foram citados.

"Leiam os clássicos" seria a mensagem que se deixaria para os pesquisadores em formação e também para aqueles que já se julgam formados. Mas, mesmo depois de nossa discussão,

[...] se alguém objetar que não vale à pena tanto esforço (para ler os clássicos), citarei Cioran (não um clássico, pelo menos por enquanto, mas um pensador contemporâneo que só agora começa a ser traduzido na Itália): 'Enquanto era preparada a cicuta, Sócrates estava aprendendo uma ária com a flauta. 'Para que lhe servirá?', perguntaram-lhe. 'Para aprender esta ária antes de morrer. (CALVINO, 1999, p. 16)

Importante que a ária ${ }^{8}$ seja apreendida por $\mathrm{si}$ mesmo, e não que seja somente ouvida quando os outros a tocam. Aprender a ária pode ser uma interessante analogia para se pensar como o sujeito precisa se colocar diante da estrutura. Que os pesquisadores que se atêm apenas a ouvir a ária, seja de perto ou de longe, reconheçam a importância de tocá-la por si mesmos. Mas não qualquer ária, afinal, ela é uma composição musical comumente escrita para um cantor solista (HOLST, 1987). Sendo assim, ela é sua, o clássico é seu. Ele pode também ser nosso. Pois a ária pode também ser escrita para mais de um cantor, pode ser um dueto, um terceto, um quarteto, quinteto, sexteto, e assim por diante (HOLST, 1987).

Os clássicos "[...] servem para entender quem somos e aonde chegamos [...]" (CALVINO, 1999, p. 16). "Quem somos e aonde chegamos" traz uma ideia de dinâmica e de movimento, e é justamente associada a essa ideia que está a nossa defesa de que os clássicos, embora considerados por muitos como sendo atemporais, sejam historicamente considerados. Defende-se o perspectivismo ao se olhar para as obras dos clássicos, pois essas não podem ser consideradas de forma desvinculada de seus contextos históricos e sociais. Os clássicos, embora possam nos trazer reflexões que soem contemporâneas, falaram para uma determinada época e para determinados contextos, até mesmo geográficos.

Considerando essas perspectivas, e também a subjetividade que está envolvida nas escolhas pelos clássicos, que se forme, assim, nossa própria biblioteca de clássicos, como sugere Calvino (1999). E se um dia nos tornarmos um desses clássicos, que se passe a reconhecer hoje não apenas o aspecto político envolvido em nossas teorias, como também as próprias relações de poder que existem entre pesquisador e pesquisado ao fazer pesquisas empíricas (WRAY-BLISS, 2003), pois nossos relatos de pesquisa podem se transformar em teorias adotadas por muitos como os seus clássicos.

Reforça-se, assim, a importância não só de ser ler os clássicos, mas também de lê-los diretamente e 
não apenas por intermédio de terceiros, bem como a importância de se escolher cuidadosamente as traduções desse clássico para leitura. Por fim, é possível considerar como possíveis desdobramentos desse ensaio, se aceitos forem nossos discursos, se com eles alguém se identificar, contribuições para um não eterno replicar no fazer ciência - já que há certo colonialismo epistêmico na América Latina, como discute Ibarra-Colado (2006). Inicialmente, pode-se pensar que considerar os clássicos seja, ao contrário, uma forma de se prender "ao passado" e de ser replicante. Contudo, para que novos caminhos teóricos e práticos sejam encontrados no fazer ciência, defende-se exatamente a importância de se entender os clássicos. Munidos de melhores ferramentas de análise a partir dessa compreensão, é possível não só nos conhecer melhor como pesquisadores (a identidade para si), como analisar nossa importância no campo do conhecimento (a identidade para o outro). Reconhecida, por sua vez, tal importância, podemos estar mais cientes da responsabilidade de se fazer ciência, não nos contentando com o mero replicar.

\section{REFERÊNCIAS}

ARCHER, M. S. Agents: active and passive. In: ARCHER, M. S. Being human: the problem of agency. Cambridge: Cambridge University Press, 2000. p. 253-281.

Disponível em: <http:/catdir.loc.gov/catdir/samples/ cam031/00031287.pdf> . Acesso em: 21 jul. 2011.

\section{BERGER, P.; LUCKMANN, T. A construção social}

da realidade: tratado de Sociologia do Conhecimento. Petrópolis: Vozes, 1985. 247 p.

BOURDIEU, P. A economia das trocas simbólicas. Perspectiva: São Paulo, 2006. 361 p.

$$
\text { O campo científico. In: ORTIZ, R. A sociologia }
$$

de Pierre Bourdieu. São Paulo: Olho D’água, 2003. p. 122-155.

O poder simbólico. Rio de Janeiro: Bertrand Brasil, 1998. 311 p.

Os usos sociais da ciência: por uma sociologia clínica do campo científico. São Paulo: UNESP, 2004. 86 p.
CALVINO, I. Por que ler os clássicos? Tradução Nilson Moulin. São Paulo: Companhia das Letras, 1999. 279 p.

CARRIERI, A. P.; PAES DE PAULA, A. P.; DAVEL, E. Identidade nas organizações: Múltipla? Fluida? Autônoma? Organizações \& Sociedade, Salvador, v. 15, n. 45, abr.-jun. 2008.

CASTELLS, M. O poder da identidade. São Paulo: Paz e Terra, 2000. 530 p.

CHASIN, J. Marx: estatuto ontológico e resolução metodológica. In: TEIXEIRA, F. J. S. Pensando com Marx. São Paulo: Ensaio, 1995. p. 335-537.

CIAMPA, A. da C. A estória do Severino e a história da Severina: um ensaio de psicologia social. São Paulo: Brasiliense, 2001. 245 p.

CUNHA, P. F. Reler o direito clássico: um desafio jurídico do séc. XXI. Grécia e Roma, fontes e exemplos da juridicidade. Revista Campo Jurídico, Barreiras, n. 1, p. 151-162, mar. 2013.

DUBAR, C. A socialização: construção das identidades sociais e profissionais. São Paulo: Martins Fontes, 2005. $343 \mathrm{p}$.

FERNANDES, M. E. R.; MARQUES, A. L.; CARRIERI, A. P. Elementos para a compreensão dos estudos de identidade em teoria organizacional. In: CARRIERI, A. P. et al. (Org.) Identidade nas organizações. Curitiba: Juruá, 2010. p. 29-62.

Identidade organizacional e os componentes do processo de identificação: uma proposta de integração. Cadernos Ebape.BR, Rio de janeiro, v. 7, n. 4, p. 687703, dez. 2009.

FOLHA DE SÃO PAULO. CADERNO MAIS! São Paulo, 11. abr. 1999.

FOUCAULT, M. Microfísica do poder. Rio de Janeiro: Edições Graal, 2006. 295 p.

Vigiar e punir. Petrópolis: Vozes, 2005. 262 p.

FREITAS, M. E. Identidade e identidades: somos o branco e o arco-íris. In: CARRIERI, A. P. et al. (Org.) Identidade nas organizações. Curitiba: Juruá, 2010. p. 11-14. 
HALL, S. A identidade cultural na pós-

modernidade. Rio de Janeiro: DP\&A Editora, 2006. 102 p.

HOLST, I. ABC da Música. São Paulo: Martins Fontes, 1987. $284 \mathrm{p}$.

IBARRA-COLADO, E. Organization Studies and Epistemic Coloniality in Latin America. Thinking Otherness from the Margins. Organization, London, v. 13, n. 4, p. 463-488, 2006.

INFOPEDIA. Ítalo Calvino. Porto: Porto Editora, 20032011. Disponível em: <http://www.infopedia.pt/\$italocalvino >. Acesso em: 21 jul. 2011.

JUNIOR, W. P. Guerreiro Ramos, administração e ciências sociais. Organizações \& Sociedade, Salvador, v. 17, n. 52, p. 201-208, jan.-mar. 2010.

MACHADO, H. V.; KOPITTKE, B. A identidade no contexto organizacional: perspectivas múltiplas de estudo. In: ENCONTRO DE ESTUDOS ORGANIZACIONAIS, 2, 2002, Recife. Anais... Recife: UFPE, 2002.

MATITZ, Q. R. S.; VIZEU, F. Construção e uso de conceitos em estudos organizacionais: por uma perspectiva social e histórica. Revista de Administração Pública, Rio de Janeiro, v. 46, n. 2, p. 577-598, mar.-abr. 2012.

NKOMO, S. M.; COX, T. Jr. Diversidade e identidade nas organizações. In: CALDAS, M. P.; FACHIN, R.; FISCHER, T. (Org.). Handbook de estudos organizacionais: modelos de análise e novas questões em estudos organizacionais. São Paulo: Atlas, 1999. p. 332-358.

ORGANIZAÇÕES \& SOCIEDADE. Edição especial: Alberto Guerreiro Ramos. Organizações \& Sociedade, Salvador, v. 17, n. 52, jan.-mar. 2010.

PAIVA, K. C. M.; MELO, M. C. O. L. Refletindo sobre identidades e profissão acadêmica em universidades. In: CARRIERI, A. P. et al. (Org.) Identidade nas organizações. Curitiba: Juruá, 2010. p. 87-105.

PIMENTA, S. M.; LOPES, M. R.; CORRÊA, M. L. A dialética das identidades nos processos de mudança. In: CARRIERI, A. P. et al. (Org.) Identidade nas organizações. Curitiba: Juruá, 2010. p. 63-85.
PIMENTEL, T. D.; CARRIERI, A. P. A espacialidade na construção da identidade. Cadernos Ebape.BR, Rio de Janeiro, v. 9, n. 1, p. 1-21, mar. 2011.

PRESTES, Z. R. Quando não é quase a mesma coisa: análise de traduções de Lev Semionovitch Vigotski no Brasil, repercussões no campo educacional. 295f. Tese (Doutorado). Universidade de Brasília, DF. Faculdade de Educação, Programa de Pós-Graduação em Educação, 2010.

\section{PRIBERAM. Novo dicionário Priberam da Língua}

Portuguesa. Priberam Informática, 2011. Disponível em: <http://www.priberam.pt/dlpo/>. Acesso em: 6 jul. 2011.

RAMOS, G. A nova ciência das organizações. Rio de Janeiro: FGV, 1989. 210 p.

SARAIVA, L. A. S. et al. As questões identitárias nas organizações. In: CARRIERI, A. P. et al. (Org.) Identidade nas organizações. Curitiba: Juruá, 2010. p. 17-28.

SEIXAS, R. Metamorfose ambulante. Disco Kring-Ha Bandolo, 1973.

SILVA, C. L.; ALMEIDA JR., B. R.; PAULO, A. C. Brincadeiras que meus pais brincavam: projeto educacional do CEI Neide Clarassot. Dialogia, São Paulo, v. 8, n. 2, p. 259-268, 2009.

TAJFEL, H. (Ed.). Differentiation between social groups: studies in the social psychology of intergroup relations. London: Academic Press, 1978. p. 61-76.

THIRY-CHERQUES, H. R. Pierre Bourdieu: a teoria na prática. Revista de Administração Pública, Rio de Janeiro, v. 40, n. 1, p. 27-55, jan.-fev. 2006.

WEBER, M. A Ética protestante e o espírito de capitalismo. São Paulo: Editors Schwarcz, 2004. 335 p.

Ética protestante e o espírito capitalista. São Paulo: Cengage Learning, 2009. 187 p.

WRAY-BLISS, E. Research subjects/research subjections: exploring the ethics and politics of critical research.

Organization, London, v. 10, n. 2, p. 307-325, 2003. 


\section{NOtAS}

1 Ítalo Calvino, o autor da obra que inspirou este ensaio, foi um jornalista, contista e romancista italiano. De pais italianos, nasceu em Cuba em outubro de 1923 e, ainda criança, retornou à Itália. "Em 1940, e em consequência da deflagração da Segunda Guerra Mundial, Calvino foi recrutado para a Mocidade Fascista, mas desertou pouco tempo depois, refugiando-se nas montanhas da Ligúria, onde se juntou à Resistência Comunista" (INFOPEDIA, 2011). Formou-se no curso de Literatura em 1947, ano em que publicou seu primeiro romance, que foi seguido por várias outras obras. Faleceu em 1985, em Siena, por causas naturais (INFOPEDIA, 2011). É enquadrado dentro da tradição literária modernista.

2 O habitus é um sistema de disposições duráveis, transferíveis e socialmente constituídas que são incorporadas aos agentes, orientando e dando significado às suas ações e representações (BOURDIEU, 1998; 2003). O habitus constitui a forma com que o indivíduo percebe, julga e valoriza o mundo. (THIRY-CHERQUES, 2006)

3 Utilizamos aqui uma abordagem bourdieusiana no que se refere à consideração do campo intelectual como um campo de poder. Não aprofundamos na teoria do autor neste ensaio, o que demandaria a abordagem dos principais conceitos do autor que, além de campo, seriam capital, habitus, doxa, nomos, illusio e hexis.

4 Telefone sem fio é uma brincadeira popular em que as crianças se colocam em fila, lado a lado. A primeira da fila transmite uma mensagem ao aluno seguinte, "[...] falando baixinho no ouvido até chegar ao último da fila que dirá para todos a mensagem que recebeu" (SILVA; ALMEIDA JR.; PAULO, 2009, p. 265). Nesse processo, a mensagem pode, ao final, chegar modificada.

5 Teórico político alemão, que é considerado um fiel intérprete da obra de Marx e Engels. "[...] líder e principal teórico do Partido Social-Democrático dos Trabalhadores Alemães. A influência de Kautsky foi enorme. Segundo o historiador francês Georges Haupt, pela seleção dos textos que considerava importantes de Marx e pela concatenação de tais textos, foi Kautsky quem criou o 'marxismo'" (termo que Marx recusava). (KONDER, 2003, p. 4)
6 A Folha de São Paulo convidou dez intelectuais para construir uma lista com os cem melhores livros de não ficção e ensaios publicados no século XX, sendo que Ética Protestante e o Espírito do Capitalismo ficou em primeiro lugar. Max Weber, clássico, também ocupa a terceira posição da lista com a obra Economia e Sociedade. (FOLHA DE SÃO PAULO, 1999)

7 Esses dois trechos estão destacados entre aspas porque retiramos dos comentários de um dos avaliadores da primeira versão deste ensaio teórico, que nos fez provocações a respeito da questão referida.

8 Composição musical. (HOLST, 1987) 